\title{
O LOCAL E A PESQUISA EM EDUCAÇÃO AMBIENTAL: A CIDADE COMO LOCAL E CONTEXTO DE ENSINO E AÇÃO
}

Denis Barros Carvalho ${ }^{1}$

Resumo: O objetivo desta pesquisa foi investigar como as Dissertações e Teses abordam a Educação Ambiental em âmbito municipal, relacionando as cidades estudadas com os locais de produção e, com isso, analisando a endogenia e a exogenia desses trabalhos, levando em conta os níveis municipal, estadual e regional. A pesquisa foi realizada de acordo com a metodologia preconizada por Ferreira (2002) e Romanowski e Ens (2006), acrescida de uma classificação quanto ao caráter endógeno ou exógeno das teses e dissertações em nível municipal, estadual e regional. Inicialmente, foram selecionados 741 trabalhos, entre teses e dissertações, tendo como entrada a palavra Educação Ambiental no título e/ou no resumo. Em um segundo momento, mediante a leitura dos resumos e dos sumários, 53 teses e dissertações que abordavam a Educação Ambiental, em âmbito municipal, foram selecionados. Outro critério utilizado para a seleção dos textos foi a disponibilidade integral para leitura e cópia eletrônica (download). Uma análise descritiva do material foi feita e o mesmo foi classificado quanto ao caráter endógeno/exógeno em nível municipal, estadual e regional. Todas as regiões, com exceção da Norte, possuem produção (teses mais dissertações) endopoética maior do que exopoética. Goiás é o estado com maior produção endopoética.

Palavras-Chave: Pesquisa em Educação Ambiental. Teses e Dissertações endopoéticas e exopoéticas. Cidade.

\section{THE LOCAL AND RESEARCH IN ENVIRONMENTAL EDUCATION: THE CITY AS A PLACE AND TEACHING AND ACTION CONTEXT}

\begin{abstract}
The objective of this research was to investigate how the dissertations and theses deal with Environmental Education at the municipal level, linking the cities studied with the places of production and, with this, analyzing the endogeny and exogeny these works, into account the levels municipal, state and regional. The research was done according to the methodology proposed by Ferreira (2002) and Romanowski and Ens (2006), aggregated with a classification of the endogenous or exogenous character of theses and dissertations at the municipal, state and regional levels. Initially, we selected 741 works, including theses and dissertations, taking as word-key the word Environmental Education in the title and / or abstract. In a second moment by reading the summaries and abstracts, 53 theses and dissertations that addressed environmental education at the municipal
\end{abstract}

\footnotetext{
${ }^{1}$ Psicólogo, Doutor em Psicologia Social e Professor do Mestrado em Desenvolvimento e Meio Ambiente da Universidade Federal do Piauí (UFPI), Teresina, Piauí, Brasil, denispsi@bol.com.br.
} 
level were selected. Another criterion for selection was the availability of full texts for reading and electronic copy (download). A descriptive analysis of the material was made and was classified as the endogenous character / exogenous at the municipal, state and regional levels. All regions of the country, with the exception of the North Region, have production (theses and dissertations ) endopoetic larger than exopoetic. Goiás is the state with the largest endopoetic production.

Keywords: Research in Environmental Education. Endopoetics and Exopoetics'Theses and Dissertations. City.

\section{EL LOCAL Y LA INVESTIGACIÓN EN EDUCACIÓN AMBIENTAL: LA CIUDAD COMO LOCAL Y CONTEXTO DE ENSEÑANZA Y ACCIÓN}

Resumen: El objetivo de esta investigación fue investigar como las Disertaciones y Tesis abordan la Educación Ambiental en el ámbito municipal, relacionando las ciudades estudiadas con los locales de producción y, con esto, se analiza la endogenia y la exogenia de esos trabajos, tomando en consideración los niveles municipal, estadual y regional. La investigación se realizó de acuerdo con la metodología preconizada por Ferreira (2002) y Romanowski y Ens (2006), sumada a una clasificación en cuanto al carácter endógeno o exógeno de las tesis y disertaciones a nivel municipal, estadual y regional. Inicialmente, se seleccionaron 741 trabajos, entre tesis y disertaciones, teniendo como entrada la palabra Educación Ambiental en el título y/o en el resumen. En un segundo momento, mediante la lectura de los resúmenes y de los sumarios, se seleccionaron 53 tesis y disertaciones que abordaban la Educación Ambiental, en el ámbito municipal. Otro criterio utilizado para la selección de los textos fue la disponibilidad integral para lectura y la copia electrónica (download). Se hizo un análisis descriptivo del material y el mismo se clasificó en cuanto al carácter endógeno/exógeno a nivel municipal, estadual y regional. Todas las regiones, con excepción de la del Norte, poseen producción (tesis más disertaciones) endopoética mayor que exopoética. Goiás es el estado con mayor producción endopoética.

Palabras Clave: Investigación en Educación Ambiental. Tesis y Disertaciones endopoéticas y exopoéticas. Ciudad.

\section{Introdução}

A degradação ambiental e o risco de um colapso ecológico mundial têm sido questões que se impuseram à sociedade moderna a partir da década de 1960, do século passado, de modo irreversível, como sintoma de uma crise civilizatória que ameaça a pôr em xeque o caráter racional da modernidade (LEFF, 2004). A historicidade da questão ambiental se expressa na noção de ambientaliqação (BUTTEL,1992; LEITE; LOPES, 2004; ACSELRAD,2010), que define a efetiva incorporação de argumentos ambientais para legitimar práticas sociais, políticas, científicas e educacionais, entre outras (ACSELRAD,2010). 
A ambientalização do conhecimento científico começou na década de 1970 e se espraiou por áreas diversas como a Economia (MAY; LUSTOSA; VINHA, 2003), a Antropologia (HAENN; WICK, 2006), a Sociologia(HANNIGAN,2009) a Psicologia (ARAGONÉS; AMÉRIGO, 2010) e a Engenharia (BRAGA et al.,2010). Essa diversidade resultou na formação de um campo transdisciplinar denominado Ciência Ambiental (BOTKIN; KELLER, 2011). Além disso, a própria Educação se tornou “ambiental', transformando-se, ao mesmo tempo, de acordo com Carvalho, Farias e Pereira (2011), em agente e efeito da ambientalização das práticas sociais.

No Brasil, em âmbito federal, a institucionalização da Educação Ambiental começou em 1973, com a criação da Secretaria Especial do Meio Ambiente (SEMA), vinculada ao Ministério do Interior (MMA; MEC, 2005). A década de 1980 foi marcada por importantes conquistas no campo ambiental, começando com a promulgação da Lei $\mathrm{n}^{\circ}$ 6938/81 (Política Nacional de Meio Ambiente) e tendo seu ponto culminante a Constituição Federal de 1988 (SILVA-SANCHÉZ,1999 INSERIR).A lei nº 6.938, de 31 de agosto de 1981, no seu artigo segundo, inciso X, afirma, como principio, prescrever a "Educação Ambiental a todos os níveis de ensino, inclusive a educação da comunidade, objetivando capacitá-la para participação ativa na defesa do Meio Ambiente".Esse princípio serviu de inspiração para a Constituição Federal Brasileira, de cinco de outubro de 1988, que no seu artigo 225, inciso VI, determina como incumbência do poder público, "promover a Educação Ambiental em todos os níveis de ensino e a conscientização pública para a preservação do meio ambiente" (BRASIL, 1988).

$\mathrm{Na}$ década de 1990, diversas publicações dedicadas à temática ambiental e à formação de professores e pesquisadores com titulação acadêmica de pós-graduação, tanto lato sensu, como stricto sensu, com diversos cursos de especialização, mestrado e doutorado (SATO; SANTOS, 2003). Um bom exemplo disso é a criação do Mestrado em Educação Ambiental da Universidade Federal do Rio Grande do Sul (UFRG), em 1994, o primeiro curso de pós-graduação stricto sensu dedicado à Educação Ambiental no Brasil. Em 1999, foi criada a Revista Eletrônica do Mestrado em Educação Ambiental, do programa da UFRG. Torres e Maestrelli (2012) enumeram os seguintes eventos nos anos 1990 do século passado, período considerado como enraízador da Educação ambiental no Brasil: 1)1992 - a criação do Ministério do Meio Ambiente e dos Núcleos Estaduais de Educação Ambiental em todas as Superintendências Estaduais; 2) 1993 - a criação de Centros de Educação Ambiental e Grupos de Trabalho de Educação Ambiental no Ministério da Educação;1994 - a criação do Programa Nacional de Educação Ambiental (PRONEA); 1995 - a criação da Câmara Técnica Temporária de Educação Ambiental no Conselho Nacional do Meio Ambiente (CONAMA), 1996 - Inserção da Educação Ambiental no Plano Plurianual do Governo 1996/1999, a criação da comissão de Educação Ambiental no Ministério do Meio Ambiente, a criação da Comissão Interministerial de Educação Ambiental (Ministério do Meio Ambiente e Ministério da Educação) e a criação de Grupos de Trabalho de Educação no Ministério do Meio Ambiente; 1997 - Publicação dos Parâmetros Curriculares nacionais; 1999 - Promulgação da Política Nacional de Educação Ambiental (PNEA), a criação da Diretoria de Educação Ambiental no Ministério do Meio Ambiente e a implantação do Programa Nacional de Educação Ambiental.

$\mathrm{Na}$ primeira década do Século XXI, ocorreu o desenvolvimento de Políticas Públicas de inserção da Educação Ambiental nas escolas. Outro fato importante foi a criação e regulamentação do Órgão Gestor da PNEA, construindo, assim, uma base para a sua execução (MMA; MEC ,2005). Enfim, em 2012, mais precisamente no dia 15 junho de 2012, o Conselho Nacional de Educação estabeleceu, através da Resolução número 02/2012, as Diretrizes Curriculares Nacionais para a Educação Ambiental. 
$\mathrm{Na}$ década de 1980, surgiram as primeiras dissertações de mestrado no campo da Educação Ambiental, que passou a estar presente em programas de pós-graduação das mais diversas áreas do saber. A primeira tese foi defendida em 1990 (MEGID NETO, 2009). No final da década de 1990, Vasconcellos (Citado por ALVES, 2006; LORENZETTI; DELIZOICOV, 2008 ) coordenou a elaboração de um banco de dados sobre a produção acadêmica brasileira das décadas de 1980 e 1990, tendo como propósito divulgar a Educação Ambiental e as pesquisas já realizadas na área.

No início do século XXI, surgem as primeiras pesquisas do estado da arte em Educação Ambiental. De acordo com Megid Neto (2009, p. 97),

\begin{abstract}
Essas pesquisas buscam inventariar, sistematizar e avaliar a produção em determinada área do conhecimento, o que implica a identificação de trabalhos produzidos na área; a seleção e classificação dos documentos segundo critérios e categorias estabelecidos em conformidade com interesses e objetivos do pesquisador; a descrição e análise das características e tendências do material; e a avaliação dos seus principais resultados, contribuições e lacunas. (...) as pesquisas do estado da arte têm um caráter de revisão bibliográfica e,ao mesmo tempo, de especulação futura e de iluminação de novos caminhos para o campo em questão.
\end{abstract}

Os estudos sobre o estado da arte da Educação Ambiental têm crescido neste início de século, criando uma literatura volumosa e diversificada (REIGOTA, 2002, 2007; NOVICKI, 2003; FRANCALANZA et al., 2005; FRANCALANZA; AMARAL, 2006; ZAKRZEVESKI; DEFFACI; LOSEKAN, 2006; BOER, 2007; VASCO; ZAKRZEVESKI; VALDUGA, 2007; LORENZETTI, 2008; LORENZETTI; DELIZOICOV, 2008; PLANTAMURA, 2008; MEGID NETO, 2009; SOUZA; SALVI, 2009, 2012; SOUZA, 2010; CARVALHO; FEITOSA, 2011; DIAS; BONOTTO, 2011; BARBOSA, 2011; BARBOSA; ZANON, 2011). Essas pesquisas analisam, especificamente, a produção científica no campo da Educação Ambiental elaborada sob a forma de dissertações e teses.

Vários trabalhos têm chamado a atenção para o forte desequilíbrio regional da produção no campo da Educação Ambiental, fortemente concentrado nas regiões Sudeste e Sul (NOVICKI, 2003; FRANCALANZA et al., 2005; VASCO; ZAKRZEVESKI; VALDUGA, 2007; LORENZETTI, 2008; LORENZETTI; DELIZOICOV, 2008; SOUZA; SALVI, 2009, 2012; CARVALHO; FEITOSA, 2011; DIAS; BONOTTO, 2011; BARBOSA, 2011).

Os estudiosos apontam a distribuição dos cursos de pós-graduação como a principal razão para esse quadro, que não é apanágio da Educação Ambiental, já que o predomínio das regiões Sul e Sudeste se repete em outras áreas da Pós-Graduação Brasileira.

Um ponto que merece ser discutido refere-se ao fato de as pesquisas apontarem a distribuição da produção em relação às regiões, estados e instituições que abrigam as dissertações e teses sobre Educação Ambiental. Pouco se sabe, contudo, sobre os lugares investigados nessas produções de Mestrados e Doutorados. É possível, contudo, relacionar os lugares estudados com os lugares de produção, mediante o uso dos conceitos de produção endógena e produção exógena.

A partir do conceito de desenvolvimento endógeno, desenvolvido por, entre outros, Amaral Filho (2001) e do conceito de exogenia discursiva, de Richter (2008), desenvolvemos o conceito de produção endógena e exógena. A Figura 1 apresenta, de modo esquemático, esse conceito. 
A produção endógena é a que ocorre no contexto do local pesquisado. Ex: a tese Percep̧cão e Caracterização ambientais da área verde da microbacia do córrego da Água Quente (São Carlos,SP) como etapas de um processo de Educação Ambiental, de Rosa Maria Tonissi, defendida na USP de São Carlos. Esse caso ilustra, também, a endogenia municipal, pois o local pesquisado situa-se no mesmo contexto municipal do local de produção. A endogenia estadual pode ser vista na tese Educaşão e Sustentabilidade: assentamento Maria da Paz-João Câmara/RN, defendida na UFRN, em Natal, por Hiramiris de Paula. O local estudado e a cidade em que a tese foi produzida ficam no mesmo Estado. Por fim, a tese Educaşão, Saúde e meio Ambiente: uma pesquisa-ação no distrito de Lauaretê do município de São Gabriel da Cachoeira, $A M$, de Renata Toledo, defendida na USP, São Paulo, representa o resultado de uma produção Exógena Regional, pois o local estudado e o local de produção pertencem a regiões distintas. Em síntese, temos que:

1) Quando o foco da tese ou da dissertação é um dado local (um parque, uma cidade, um rio) apresenta-se a questão do local de estudo.

2) A comparação entre o local de estudo e o local em que é produzida a tese ou dissertação nos permite classificar a produção em endógena ou exógena, tendo como níveis de análise o municipal, o estadual e o regional.

3) Uma produção endógena municipal pode ser compreendida, também, como uma produção de endogenia absoluta, pois possuirá, necessariamente, endogenias estadual e regional.

4) Uma produção exógena regional pode ser compreendida, também, como uma produção de exogenia absoluta, pois possuirá, necessariamente, exogenias municipal e estadual.

Dessa forma, teremos dissertações e teses Endopoéticas, quando forem produzidas no mesmo contexto municipal,estadual e regional do local que tiveram como foco de estudo e dissertações e teses exopoéticas, quando o local de produção não for o mesmo município,estado ou região do local focado na pesquisa 
Figura 1 - Níveis de Produção Endógena e Exógena

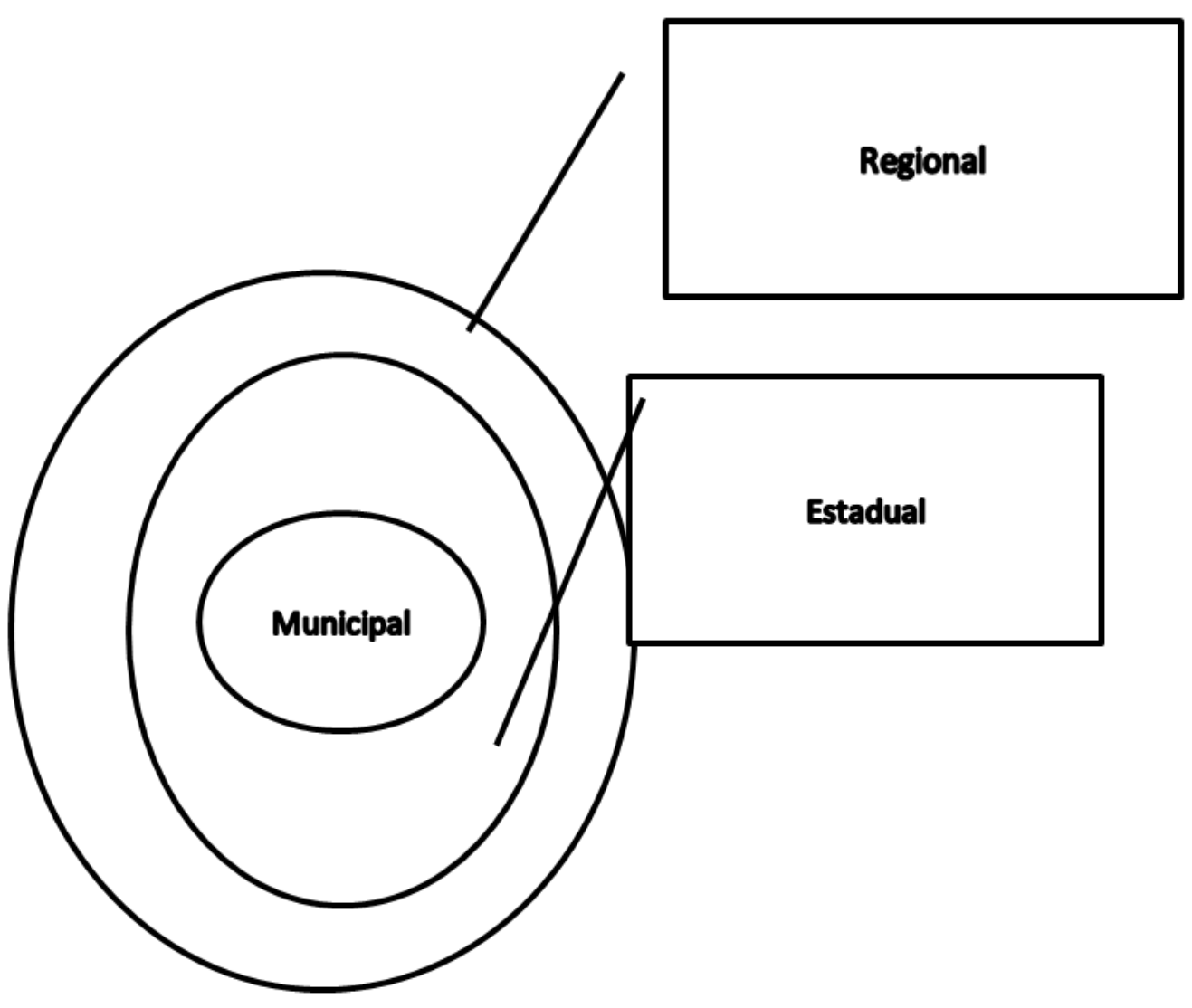

A questão do local pode ser entendida no contexto da globalização. Ulrike Schuerkens (2003) aponta que, paradoxalmente, o processo de Globalização produziu uma intensificação dos esforços de manutenção de tradições culturais locais. Ele acrescenta, ainda, que o elemento essencial do local é a vida cotidiana, espaço de reprodução da vida, de atividades repetitivas, mas, também, de momentos de transformação. Para Lefebvre (1999), o cotidiano integra a ordem próxima (relações de indivíduos em grupos mais ou menos amplos e as recíprocas relações desses grupos). Entre essa ordem próxima e a ordem distante (dominada por grandes instituições, tais como Estado, Igreja, Sistema Econômico), encontra-se a cidade. De acordo com o pensador francês:

A cidade é uma mediagão entre as mediações. Por conter a ordem próxima, ela a mantém; sustenta relações de produção e de propriedade; é o local de sua reprodução. Contida na ordem distante, ela se sustenta; encarna-a; projeta-a sobre um terreno ( o lugar) e sobre um plano, o plano da vida imediata; a cidade inscreve essa ordem, prescreve-a, escreve-a, texto num contexto mais amplo e inapreensível como tal e não ser para meditação(...) (LEFEBVRE,1999, p.46, Grifos do autor).

Uma discussão sobre a relação local x Global na pesquisa sobre Educação Ambiental foi feita por Dias e Bonotto (2011), a partir de um estudo sobre teses e dissertações que faziam referência a essas escalas; essas autoras encontraram um predomínio de pesquisas que tinham como abrangência a escala local/regional.

Uma perspectiva diferente, que foi adotada neste trabalho, é focar o local a partir da questão do local na educação (VIEIRA, 2011). É o município que assume a Educação Infantil e o Ensino Fundamental, sendo assim ente importantíssimo no Sistema de Ensino 
Brasileiro. O objetivo desta pesquisa foi, justamente, investigar como as Dissertações e Teses abordam a Educação Ambiental em âmbito municipal, relacionando as cidades estudadas com os locais de produção e, com isso, analisando a endogenia e a exogenia dos trabalhos, levando em conta os níveis municipal, estadual e regional.

\section{Procedimentos metodológicos}

A pesquisa foi realizada de acordo com a metodologia preconizada por Ferreira (2002) e Romanowski e Ens (2006 INSERIR),acrescida de uma classificação quanto ao caráter endógeno ou exógeno das teses e dissertações em nível municipal,estadual e regional:

2.1. 1므 Fase - Levantamento e caracterização: As teses foram selecionadas a partir de consultas a dois bancos de dados: A Biblioteca Digital de Teses e Dissertações (BDTD), do Instituto Brasileiro de Informação em Ciência e Tecnologia, e a Biblioteca Digital Domínio Publico, pertencente ao Ministério da Educação. Assim, inicialmente, foram selecionados 741 trabalhos, entre teses e dissertações, tendo como entrada a palavra Educação Ambiental no título e/ou no resumo. Em um segundo momento, mediante a leitura dos resumos e dos sumários, 53 teses e dissertações que abordavam a Educação Ambiental em âmbito municipal foram selecionadas. Outro critério utilizado para a seleção dos textos foi a disponibilidade integral para leitura e cópia eletrônica (download).

2.2. $2^{a}$ Fase: Análise Descritiva do material e classificação quanto ao caráter endógeno/ exógeno em nivel municipal, estadual e regional: as teses e dissertações foram classificadas em função das cidades temas de seus estudos, em relação ao estado e à região que pertenciam e, também, em relação às cidades, estados e regiões das instituições de ensino superior em que foram defendidas.

\section{Resultados e Discussão}

Alguns indicadores gerais: a) teses endopoéticas indicam amadurecimento na formação de pesquisadores locais que, em nível de doutorado, estarão capacitados a desenvolverem novas pesquisas de modo autônomo. Indicam, também, a possibilidade de pesquisas mais robustas, com dados e análises produzidos com mais vagar, em melhores condições de elaboração; b) a predominância de teses e dissertações exopoéticas indica um estágio ainda heterônimo da produção.

$\mathrm{Na}$ tabela 1, temos um retrato panorâmico das regiões brasileiras. Observem que a região Norte é a que menos apresenta trabalhos (somente 5), tem a predominância de produções exopoéticas e não possui nenhuma tese endopoética. Somado a isso, a produção se concentra em um estado, Tocantins (ver Tabela 2). A superioridade da região Sudeste não é tão significativa e a Região Centro-Oeste supera a Região Sul, graças à expressiva produção versando sobre cidades de Goiás (Ver Tabela 4). Todas as regiões, com exceção da Norte, possuem produção (teses mais dissertações) endopoética muito maior do que a exopoética. As regiões Norte e Centro-Oeste não possuem teses endopoéticas. 
Tabela 1 - As pesquisas por região

\begin{tabular}{lllllc}
\hline \multicolumn{1}{c}{ Região } & $\begin{array}{l}\text { Teses } \\
\text { Endopoéticas }\end{array}$ & $\begin{array}{c}\text { Dissertações } \\
\text { Endopoéticas }\end{array}$ & $\begin{array}{l}\text { Teses } \\
\text { Exopoéticas }\end{array}$ & $\begin{array}{l}\text { Dissertações } \\
\text { Exopoéticas }\end{array}$ & Total \\
\hline $\begin{array}{l}\text { Norte } \\
\text { Nordeste }\end{array}$ & 0 & 2 & 1 & 2 & 5 \\
Centro- & 0 & 10 & 0 & 0 & 11 \\
Oeste & & 11 & 0 & 1 & 12 \\
Sudeste & 1 & & & & \\
Sul & 2 & 13 & 0 & 0 & 14 \\
Total & 4 & 9 & 0 & 0 & 11 \\
\hline
\end{tabular}

Fonte: os autores

$\mathrm{Na}$ Região Norte, o Estado de Tocantins possui o maior número de trabalhos, incluindo a única tese sobre a região (Tabela 2). Na verdade, essa é a única tese exopoética absoluta encontrada na pesquisa; versa sobre a cidade de Palmas e foi realizada na Universidade Federal de Goiás. Não há exogenia estadual na região Norte.

Tabela 2 -As pesquisas sobre a região Norte

\begin{tabular}{lccccc}
\hline \multicolumn{1}{c}{ Estado } & $\begin{array}{c}\text { Teses } \\
\text { Endopoéticas }\end{array}$ & $\begin{array}{c}\text { Dissertações } \\
\text { Endopoéticas }\end{array}$ & $\begin{array}{c}\text { Teses } \\
\text { Exopoéticas }\end{array}$ & $\begin{array}{c}\text { Dissertações } \\
\text { Exopoéticas }\end{array}$ & Total \\
\hline Pará & 0 & 1 & 0 & 0 & 1 \\
Tocantins & 0 & 1 & 1 & 1 & 3 \\
Acre & 0 & 0 & 0 & 1 & 1 \\
Total & 0 & 2 & 1 & 2 & 5 \\
\hline
\end{tabular}

Fonte: os autores

O Ceará é um dos três Estados que possui tese endopoética, sendo os outros dois São Paulo e Santa Catarina. A produção é bem distribuída e não há nenhuma tese exopoética na região Nordeste (Tabela 3). A ausência do Estado da Paraíba chama atenção. Nenhuma produção sobre duas cidades importantes na região: João Pessoa e Campina Grande. Mas, certamente, a ausência mais significativa é a de Salvador-BA. Bahia, Paraíba e Maranhão não tiveram nenhuma produção sobre a Educação Ambiental em suas cidades. Quanto à exogenia estadual, há uma dissertação sobre Maceió, defendida na Universidade Federal da Paraíba, em João Pessoa, e uma sobre Acaraú-CE, defendida na Universidade Federal do Rio Grande do Norte, em Natal.

Tabela 3 - As pesquisas sobre a Região Nordeste

\begin{tabular}{cccccc}
\hline Estado & $\begin{array}{c}\text { Teses } \\
\text { Endopoéticas }\end{array}$ & $\begin{array}{c}\text { Dissertações } \\
\text { Endopoéticas }\end{array}$ & $\begin{array}{c}\text { Teses } \\
\text { Exopoéticas }\end{array}$ & $\begin{array}{c}\text { Dissertações } \\
\text { Exopoéticas }\end{array}$ & Total \\
\hline Pernambuco & 0 & 2 & 0 & 0 & 2 \\
Alagoas & 0 & 1 & 0 & 1 & 2 \\
Piauí & 0 & 1 & 0 & 0 & 1 \\
Sergipe & 0 & 2 & 0 & 0 & 2 \\
Ceará & 1 & 0 & 0 & 0 & 2 \\
Rio Grande do & 0 & 2 & 0 & 2 & 11 \\
Norte & 1 & 8 & 0 &
\end{tabular}

$\mathrm{Na}$ região Centro-Oeste não há produção de teses: todos os estudos são dissertações (Tabela 4). A produção é maciçamente concentrada no Estado de Goiás. Não há nenhum estudo sobre Brasília. É a segunda região em produção, sendo Goiás o estado que mais tem trabalhos dentre todos pesquisados. Há apenas um trabalho exógeno: uma 
dissertação sobre a cidade de São Gabriel do Oeste - MS defendida na Universidade Federal de Uberlândia.

Tabela 4 - As pesquisas sobre a Região Centro-Oeste

\begin{tabular}{lccccc}
\hline \multicolumn{1}{c}{ Estado } & $\begin{array}{c}\text { Teses } \\
\text { Endopoéticas }\end{array}$ & $\begin{array}{c}\text { Dissertações } \\
\text { Endopoéticas }\end{array}$ & $\begin{array}{c}\text { Teses } \\
\text { Exopoéticas }\end{array}$ & $\begin{array}{c}\text { Dissertações } \\
\text { Exopoéticas }\end{array}$ & Total \\
\hline Mato Grosso do sul & 0 & 2 & 0 & 1 & 3 \\
Goiás & 0 & 9 & 0 & 0 & 9 \\
Total & 0 & 11 & 0 & 1 & 12 \\
\hline \multicolumn{7}{r}{ Fonte: os autores }
\end{tabular}

Na região Sudeste, importa destacar a existência de uma única tese endopoética, embora não exista nenhum exopoética (Tabela 5). Isso significa que não há interesse em pesquisas de doutorado em investigar como se estrutura a Educação Ambiental no âmbito municipal. Embora seja uma região tradicionalmente destacada na produção de pesquisas de teses e dissertações, no que diz respeito ao nosso tema, a Região Sudeste possui menos teses do que a Região Sul.

Tabela 5 - As pesquisas sobre a Região Sudeste

\begin{tabular}{lccccc}
\hline \multicolumn{1}{c}{ Estado } & $\begin{array}{c}\text { Teses } \\
\text { Endopoéticas }\end{array}$ & $\begin{array}{c}\text { Dissertações } \\
\text { Endopoéticas }\end{array}$ & $\begin{array}{c}\text { Teses } \\
\text { Exopoéticas }\end{array}$ & $\begin{array}{c}\text { Dissertações } \\
\text { Exopoéticas }\end{array}$ & Total \\
\hline Rio de Janeiro & 0 & 3 & 0 & 0 & 3 \\
São Paulo & 1 & 5 & 0 & 0 & 6 \\
Minas Gerais & 0 & 4 & 0 & 1 & 5 \\
Total & 1 & 13 & 0 & 1 & 14 \\
\hline \multicolumn{7}{r}{ Fonte: os autores }
\end{tabular}

Na Região Sul, todos os Estados apresentaram produção, embora seja necessário levar em conta que essa é a região com o menos número de unidades federativas (Tabela 6). O números de teses é igual: uma endopoética e outra exopoética de nível estadual, conservando o caráter endopoético regional da produção.Trata-se da tese A formação moral e os princípios éticos na educação ambiental: uma análise dos projetos das escolas municipais de Curitiba, desenvolvida na Universidade Federal de Santa Catarina. O Rio Grande do Sul possui o único doutorado em Educação Ambiental do Brasil, oferecido pela Universidade Federal do Rio Grande. A cidade de Rio Grande é uma das mais estudadas da pesquisa (Tabela 7), mas apenas com trabalhos de nível de Mestrado.

Tabela 6 - As pesquisas sobre a Região Sul

\begin{tabular}{lccccc}
\hline \multicolumn{1}{c}{ Estado } & $\begin{array}{c}\text { Teses } \\
\text { Endopoéticas }\end{array}$ & $\begin{array}{c}\text { Dissertações } \\
\text { Endopoéticas }\end{array}$ & $\begin{array}{c}\text { Teses } \\
\text { Exopoéticas }\end{array}$ & $\begin{array}{c}\text { Dissertações } \\
\text { Exopoéticas }\end{array}$ & Total \\
\hline Rio Grande do Sul & 0 & 4 & 0 & 0 & 4 \\
Paraná & 0 & 2 & 1 & 0 & 3 \\
Santa Catarina & 1 & 3 & 0 & 0 & 4 \\
Total & 1 & 9 & 1 & 0 & 11 \\
\hline
\end{tabular}

Fonte: os autores

A tabela 7 apresenta o número de cidades por estados e regiões. São 16 dos 27 estados que apresentam pelo menos uma cidade estudada. Surpreendentemente, Goiás e minas Gerais são os estados com mais cidades pesquisadas. Também é de se destacar o número de cidades catarinenses estudadas, quatro, o mesmo número de cidades paulistas.

O Estado do Mato Grosso do Sul também aparece em destaque, com o mesmo número de cidades que o Estado do Rio de Janeiro: três. São 40 municípios estudados, de um total de 5.570 existentes em nosso país. A Região Sudeste foi a que teve o maior 
número de municípios estudados (12), enquanto a Região Norte foi a que teve menos (03). Vale a pena ressaltar que o Estado de Minas Gerais é o que possui o maior número de municípios dentre os Estados brasileiros: 853.

Em termos percentuais, no entanto, os Estados que se destacaram foram o Mato Grosso do Sul (3,8\% do total de municípios), Rio de janeiro (3,3\%) e Sergipe, com 2,7 por cento do total de municípios. Outro ponto que merece ser destacado é que a Região Nordeste foi a segunda em quantidade de cidades (nove) estudadas, mas nenhum estado dessa região se destaca individualmente. O número de municípios estudados em toda a Região Norte (3) é inferior ao número de municípios estudados nos Estados de Minas Gerais, Goiás e Santa Catarina. É o mesmo número de municípios estudados nos Estados do Rio de Janeiro e do Mato Grosso Sul. Em síntese, se em termos absolutos Minas Gerais tem o maior número de municípios pesquisados, em termos percentuais o Estado do Mato Grosso do Sul se destaca como o que mais teve municípios estudados em relação ao total de municípios que possui.

Tabela 7 - Número de Estados e Municípios estudados

\begin{tabular}{|c|c|c|c|}
\hline Região & Estado & $\begin{array}{l}\text { Número de } \\
\text { Municípios } \\
\text { Estudado }\end{array}$ & $\begin{array}{l}\% \text { de Municípios } \\
\text { Estudados/Estado }\end{array}$ \\
\hline Norte & Acre & 1 & $4,55 \%$ \\
\hline Norte & Pará & 1 & $0,70 \%$ \\
\hline Norte & Tocantins & 1 & $2,16 \%$ \\
\hline Nordeste & Pernambuco & 1 & $0,54 \%$ \\
\hline Nordeste & $\begin{array}{l}\text { Rio Grande do } \\
\text { Norte }\end{array}$ & 2 & $1,20 \%$ \\
\hline Nordeste & Ceará & 2 & $1,09 \%$ \\
\hline Nordeste & Alagoas & 1 & $0,98 \%$ \\
\hline Nordeste & Sergipe & 2 & $2,67 \%$ \\
\hline Nordeste & Piauí & 1 & $0,45 \%$ \\
\hline Centro-Oeste & $\begin{array}{l}\text { Mato Grosso do } \\
\text { Sul }\end{array}$ & 3 & $3,80 \%$ \\
\hline Centro-Oeste & Goiás & 5 & $2,03 \%$ \\
\hline Sudeste & Rio de Janeiro & 3 & $3,26 \%$ \\
\hline Sudeste & São Paulo & 4 & $0,62 \%$ \\
\hline Sudeste & Minas Gerais & 5 & $0,59 \%$ \\
\hline Sul & $\begin{array}{l}\text { Rio Grande do } \\
\text { Sul }\end{array}$ & 3 & $0,60 \%$ \\
\hline Sul & Paraná & 1 & $0,25 \%$ \\
\hline Sul & Santa Catarina & 4 & $1,37 \%$ \\
\hline Total & 16 & 40 & \\
\hline
\end{tabular}

Fonte: os autores 


\section{Considerações Finais}

A produção de teses e dissertações sobre Educação Ambiental, como bem mostra a literatura, reflete a concentração de programas de pós-graduação no Brasil, existente, principalmente, na região Sudeste. A produção endopoética, que indica o amadurecimento de uma cidade, estado ou região - no que diz respeito ao tema educação ambiental no contexto municipal - encontra-se bem desenvolvida em estados como Goiás e em regiões como o Nordeste. Isso não significa que, quando consideramos a produção levando em conta os locais pesquisados, a concentração desapareça. Seria preciso investigar outros tipos de locais, tais como parques, rios, florestas para avaliar.

Outra questão importante é que não sabemos se os trabalhos, efetivamente, se tornam referências para novas pesquisas. Seria preciso desenvolver futuras pesquisas sobre o impacto das teses e dissertações em produções endógenas posteriores. Por fim, e talvez com mais importância, reconhecemos que este trabalho não discutiu a qualidade da produção estudada. Mas algumas considerações podem ser feitas: 1) a disponibilidade integral do texto para acesso e cópia na Internet é uma forma de qualidade, a de acesso; 2) há uma qualidade intrínseca ao tema, mas que não é sempre enriquecida com as estratégias metodológicas utilizadas. Assim, é possível ver que somente uma análise qualitativa dos trabalhos nos permitiria investigar essa questão.

\section{Referências}

ACSELRAD, H. Ambientalização das lutas sociais - o caso do movimento por justiça ambiental. Estudos Avançados, São Paulo, v.24, n.68, p.103-119, . 2010.

ALVES, L. A Educação Ambiental e a pós-graduação: um olhar sobre a produção discente. 2006.297 fls. Dissertação (Mestrado em Educação) - Pontifícia Universidade Católica, Rio de Janeiro, 2006.

AMARAL FILHO, J. Endogeneização no desenvolvimento econômico regional e local. Planejamento e Politicas Públicas, Brasília, v.23, 23, p.261-286, Jun. 2001.

ARAgONÉS, J.I.; AMÉRIGO, M. (Orgs.). Psicología Ambiental. 3ed. Madrid: Pirámide, 2010. BARBOSA, L. Sobre o que pesquisam as produções acadêmicas em Educação Ambiental nos programas de pós-graduação em Educação e ensino de Ciências do Centro-Oeste brasileiro: temáticas investigadas. Revista Eletrônica do Mestrado em Educaşão Ambiental, Rio Grande, v.27, 1, p.168-183, Jun/Dez. 2011.

BARBOSA, L.; ZANON, A. A Pesquisa em Educação Ambiental no Centro-Oeste brasileiro: um estudo da produção acadêmica das áreas de Educação e ensino de Ciências. VI ENCONTRO DE PESQUISA E EDUCAÇÃO AMBIENTAL, Ribeirão Preto: ABRAPEC, 2011. CD-ROOM.

BOER, N. Educaşão Ambiental e visões de mundo: uma análise pedagógica e epistemológica. Florianópolis: UFSC, 2007.

BOTKIN, D.; KELLER, E. Ciência Ambiental: Terra, um planeta vivo. Rio de Janeiro: LTC, 2011.

BRAGA, B. et al. Introdução à Engenharia Ambiental: o desafio do desenvolvimento sustentável. São Paulo: Prentice Hall, 2010 .

BRASIL. Casa Civil. Constituição da República Federativa do Brasil, de 5 de outubro de 1988. Brasília, 1988. Disponível em: < http://www.planalto.gov.br/ccivil_03/constituicao/constituicao.htm>. Acesso em: 19 jan. 2014. 
BUTTEL, F. Environmentalization: Origins, Processes, and Implications for Rural Social Change. Rural Sociology, v.57, n. 1, p.1-27, mar. 1992.

CARVALHO, D.; FEITOSA, C. A produção brasileira de teses sobre a Educação Ambiental na Biblioteca Digital de Teses e Dissertações (BDTD):Uma análise temática. Ambiente e Educaşão, Rio Grande, v.16, n.1, p.45-47, 2011.

CARVALHO, I.; FARIAS, C.; PEREIRA,M. A missão "ecocivilizatória" e as novas moralidades. Ambiente \& Sociedade, São Paulo, v.14, n.2, p.35-49, Dez. 2011.

DIAS, G.; BONOTTO, D. Educação Ambiental e as escalas local e global apresentadas em teses e dissertações. In VI ENCONTRO DE PESQUISA E EDUCAÇÃO AMBIENTAL, Ribeirão Preto: ABRAPEC, 2011. CD-ROOM.

FERREIRA, N. As pesquisas denominadas "Estado da arte". Educação \& Sociedade, Campinas, v.23, n.79, p.257-272, Agost. 2002.

FRANCALANZA, H.; AMARAL, I.; MEGID NETO, J.; EBERLIN, T. A Educação Ambiental no Brasil: panorama inicial da produção acadêmica. In ENCONTRO DE PESQUISA EM EDUCAÇÃO EM CIÊNCIAS, 5, Bauru, 2005. Anais... Bauru: ABRAPEC, 2005. CD-ROOM.

FRANCALANZA, H.; AMARAL, I. A educação ambiental no Brasil: análise da produção acadêmica (Dissertações e teses - 1a Fase). Campinas: UNICAMP, 2006.

HAENN,N.; WILK, R. (Orgs.). The Enviroment in Anthropology: a Reader in Ecology, Culture and Sustainable Living. New York: New York University Press, 2006.

HANNIGAN, J. Sociologia Ambiental. Petrópolis: Vozes, 2009.

LEFEBVRE, H. A cidade do capital. Rio de janeiro: DP \& A, 1999.

LEFF, Enrique. Saber ambiental: Sustentabilidade, racionalidade, complexidade e poder. 3ed. Petrópolis: Vozes, 2004.

LEITE LOPES, J. Sobre processos de "ambientalização" dos conflitos e sobre dilemas da participação. Horizontes Antropológicos, Porto Alegre, v.12, n. 25, p.31-64, Jan/Jun. 2006.

LORENZETTI, L.; DELIZOICOV, D. La producción académica brasileña en Educación Ambiental. Utopia y Práxis Latinoamericana, Maracaibo, v.14, n.44, p.85-100, Mar. 2008.

LORENZETTI, L. Estilos de pensamento em Educação Ambiental:uma análise a partir das dissertações e teses. Florianópolis: UFSC, 2008.

MAY, P.; LUSTOSA, M.C.; VINHA, V. (Orgs). Economia do Meio Ambiente: teoria e prática. Rio de Janeiro: Campus, 2003.

MEGID NETO, J. Educação Ambiental como campo de conhecimento: a contribuição das pesquisas acadêmicas para a sua consolidação no Brasil. Pesquisa em Educação Ambiental, São Paulo, v.4, n.2, p.95-100, 2009.

MINISTÉRIO DA EDUCAÇÃO; MINISTÉRIO DO MEIO AMBIENTE. Programa Nacional de Educação Ambiental - ProNEA. 3ed. Brasília: Ministério do Meio Ambiente, 2005. 
NOVICKI, V. Abordagens teórico-metodológicas na pesquisa discente em Educação Ambiental: programas de pós-graduação em Educação no Rio de Janeiro (1981-2002). In REUNIÃO DA ANPED, 26, Poços de Caldas, 2003. CD-ROOM.

PLANTAMURA,V. Educação Ambiental no Amazonas: a produção discente nos programas de pós-graduação e as possibilidades de pesquisa no enfoque crítico-emancipatório. In REUNIÃO DA ANPED, 21, Caxambu, 2008.

REIGOTA, M. El estado del arte de la Educación ambiental en Brasil. Tópicos en Educación ambiental, Ciudad del México, v.4, n.11, p.49-62, 2002.

REIGOTA, M. O estado da arte da pesquisa em Educação Ambiental no Brasil. Pesquisa em Educação Ambiental, São Paulo, v.2, n.1, p.33-66, 2007.

RICHTER, M. Aquisição, representação e atividade. Santa Maria: PPGL-Editores, 2008.

ROMANOWSKI, J. P.; ENS, R. T. As pesquisas denominadas do tipo "estado da arte" em educação. Diálogo Educacional,Curitiba, v. 6, n. 19, p. 37-50, set./dez., 2006.

SILVA-SÁNCHEZ,S. Política de meio ambiente no Brasil: a construção da cidadania ambiental.Plural, São Paulo,v.6, n. 1, p.20-46, Jan/Jun. 1999.

SATO, M.; SANTOS, J. Tendências nas pesquisas em Educação Ambiental. In NOAL, F.; BARCELLOS,V.(Orgs.). Educação Ambiental e cidadania: cenários brasileiros. Santa Cruz do Sul: EDUNISC, 2003. p.253-283.

SCHUERKENS,U. The sociological and anthropological study of globalization and localization. Current Sociology, Chicago, v.51, n.3/4, p.209-222, 2003.

SOUZA, D.; SALVI, R. Cartografia da pesquisa sobre formação de professores em Educação Ambiental nas áreas de Educação e de Ensino de Ciências e Matemática. Revista brasileira de Pesquisa em Educação em Ciências, Florianópolis, v.12, n.2, p.45-69, 2012.

SOUZA, D.; SALVI, R. A pesquisa em Educação Ambiental no Brasil (2003-2007) da PósGraduação Stricto sensu - o contexto de uma investigação sobre formação de professores. In VII ENCONTRO NACIONAL DE PESQUISADORES EM EDUCAÇÃO EM CIÊNCIAS, 7, Florianópolis, 2009. Florianópolis: UFSC, 2009. CD-ROOM.

SOUZA, D. Cartografia da Educaşão Ambiental nas pós-graduações stricto sensu brasileiras (2003-2007): ênfase na pesquisa das áreas de Educação e de Ensino de Ciências sobre a formação de professores. Londrina: Universidade Estadual de Londrina, 2010.

TORRES, J.; MAESTRELLI, S. Atributos da Educação Ambiental escolar no contexto educacional brasileiro: do movimento ambientalista internacional ao nacional.Revista Eletrônica do Mestrado em Educaşão Ambiental, Porto Alegre, v. 28, n.1, p.114-132, Jan/Jun.2012.

VASCO, A.; ZAKRZEVESKI, S.; VALDUGA, A. A pesquisa em Educação Ambiental no Brasil: um estudo dos programas de pós-graduação Strictu Senso. In CONGRESSO DE ECOLOGIA DO BRASIL, 7, Caxambu, 2007. CD-ROOM.

VIEIRA, S. Poder local e Educação no Brasil: dimensões e tensões. Revista Brasileira de Política e Administração da Educação, Recife, V. 27, n. 1,p.12-133, Jan/Jun, 2011. 
ZAKRZEVESKI, S.; DEFFACI, A.; LOSEKAN, C. A pesquisa em Educação Ambiental nos programas de pós-graduação Strictu senso: um estudo nas universidades gaúchas. Unirevistas, São Leopoldo, v.1, n.2,. 2006. Disponível em:

<http://www.unirevista.unisinos.br/_pdf/UNIrev_ZZakrzeviski.pdf>. Acesso em: 15 jan. 2012.

Artigo submetido em 13/05/2013

Artigo aprovado em 09/09/2013 